\title{
Fuzzy Expert Pricing Systems and Optimization Techniques in Marketing Science
}

\author{
Adeolu DAIRO ${ }^{\mathrm{a}, 1}$ and Krisztián SZÜCS ${ }^{\mathrm{b}}$ \\ ${ }^{\mathrm{a}, \mathrm{b}}$ Faculty of Business and Economics, University of Pecs, Hungary
}

\begin{abstract}
Despite the advancement in the mathematical models for solving and modeling marketing problems, there exists gap between model predictions and market reality. Fuzzy logic bridges this gap by providing marketers with the opportunity of combining robust human experts in the form of linguistic rules to formulate a knowledge-base. These rules are systematically developed into a marketing tool which provides intelligent pricing decision support for marketers in a dynamic and competitive environment. In this paper, these expert pricing systems which are designed and developed to help businesses in pricing decisionmaking are examined. Price-Strat, FuzzyPrice, and exPrice expert pricing systems are compared and discussed. These three expert pricing systems are explored along with their fuzzy development approach, effectiveness, and attributes in pricing products and services.
\end{abstract}

Keywords. fuzzy logic, pricing tools, marketing models.

\section{Introduction}

The advancement and advantages of working with membership function as against crisp values brought to light the importance of fuzzy logic in marketing science [1]. Marketers have a powerful tool when they leverage fuzzy logic in the development of marketing models. The fuzzy logic marketing model is a new way of carrying out marketing analysis by marketers through the emergence of "if-then" rules instead of the crisp value. With this new modeling approach, marketers are now endowed with business tools that are sustainable for driving business performance. Marketers can now respond to the dynamic and sophisticated consumer market, along with competition and other market fluctuations.

Pricing has always been one of the primary issues of every business [2]. Setting the appropriate price has an immediate effect on the company's revenue and profitability. For pricing decision-making, numerous parameters must be taken into consideration. First, the company must decide the strategic aims of its pricing moves. These can be due to the need for survival under intense competition or scarce resources. Also, the need to maximize profit and sales growth can account for the need for a price change. Having the right pricing tools and models helps marketers to respond to the needs of the customers, competition and enhance consumer customer experience toward an acceptable level of profitability $[1,2]$.

\footnotetext{
${ }^{1}$ Adeolu Dairo, Faculty of Business and Economics, University of Pecs, Rakoczi 80, Pecs H -7623, Pecs,
} Hungary; E-mail: dairo.adeolu@pte.hu. 
In this study, three Fuzzy Expert knowledge-based pricing systems are discussed. Price-Strat system [3], FuzzyPrice [4], and exPrice expert systems [5] are compared along with their fuzzy development and their focus on solving pricing issues and challenges across different sectors.

\section{Literature Review}

Many research applications in marketing have emerged using fuzzy logic as modeling techniques [6]. A prominent field of marketing in this regard is customer behavior and customer satisfaction models [7]. Fuzzy expert systems focus and deal with uncertainty by leveraging fuzzy information processing through fuzzy rules. According to Ertay and Kahraman [8], fuzzy logic models offer opportunities in evaluating relations between consumer needs and service attributes. Also, the ability to navigate through the natural language and its statements components has yielded contributions from researchers in the aspects of the product, service with quality evaluation, and group analysis $[9,10,11]$. Customer segmentation is another marketing field that has witnessed the significant application of fuzzy logic [12]. The marketing mix, pricing, and strategy are another prominent area of fuzzy applications in marketing science $[13,14,15,16]$. In all these applications, marketers have seen an increase in the gathering of marketing analysis because of the use of fuzzy logic in several aspects of marketing science.

Expert systems are considered as part of computer science that leverages the symbolic and non-algorithm approach to solve tasks $[6,7]$. These types of computer programs combine techniques and knowledge that are comparable to human experts [17]. Generally, an expert system is comprised of three essential components: the knowledge base, inference engine, and the user interface [18]. The decision-makers are the domain expert, knowledge engineer, and the user. The inference engine generates decisions following its interpretation of the knowledge of experts. The strategic expertise for solving different problems resides with the knowledge engineer who leverages the experience of previously solved problems to address the current issues [19]. Knowledge engineer requires the domain expert to think aloud and explain every step of the decision-making process during the expert system development. Knowledge engineer models the knowledge as soon as he has understood the knowledge structure. Understanding and modeling the experience is a complex task, and at the same time, one of the most critical steps in expert system development [6].

On many occasions, expert system development takes an approach similar to prototype logic [19]. This logic undergoes testing and modification [20, 21]. Also, the second to the $\mathrm{n}^{\text {th }}$ prototype will be created until an acceptable result is obtained from the expert system. Moreover, expert systems can keep many years of experience of combined marketers in the form of knowledge [7].

\section{Methodology}

In providing a clear outlook of the importance and advantages of fuzzy logic application and its associated expert systems in marketing science, this study discusses three fuzzy expert pricing tools. These pricing expert systems (Price-Strat, FuzzyPrice, and exPrice) 
leverage both descriptive and inference statistics in building the fundamentals of their fuzzy model with details of relevant components of the pricing tools $[3,4,5]$.

\section{Discussion}

During the creation of a typical fuzzy logic model, the first step is the transformation of the linguistic variables within the membership functions with the intention of a clear understanding of the variables in a fuzzy way. In that case, each of the membership functions stands for a linguistic variable with a clear definition of the associated fuzzy set along with the parameter.

\subsection{Price-Strat Expert System}

Price-Strat [3] stands out as one of the unique pricing expert systems. It is a hybrid expert system that leverages both the historical market data and commercial managers' experiences to arrive at the most appropriate pricing solution for different industries -industry, such as banking, aviation, and telecommunication. The Price-Strat pricing system performs well in reacting to the competitor's move within a competitive environment that is characterized by price wars.

As for the Price-Strat methodology, business goals and objectives for pricing decisions are first determined by the business managers. Afterward, the system generates "what-if" scenarios with regards to possible variations of prices to competitive prices. These scenarios are fed into the system, which creates the knowledge base. An adaptive predictive model is created through historical market data that are fed into the system (see Figure 1). The most appropriate price solution is generated among many proposed solutions through the questioning of the knowledge base. Price-Strat takes into consideration all variable costs, fixed cost, price, and all constraints, such as volume [3, 22].

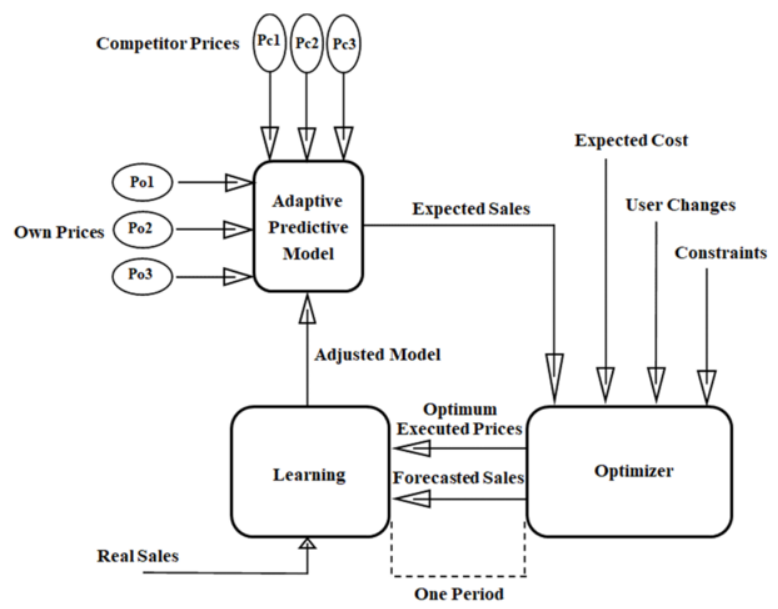

Figure. 1. Price-Strat generic system and architecture 


\subsection{FuzzyPrice Expert System}

FuzzyPrice pricing expert system combines fuzzy logic and fuzzy reasoning methods to arrive at the appropriate price combination across the product portfolio of a firm [4]. It does this with a view of aligning with the firm strategic aims while considering the strategic constraints. In this case, the inference follows the price changes of the competitors during the price wars. A unique feature of the FuzzyPrice system is that it is restricted to short and mid-term pricing and cannot be considered for long-term pricing.

FuzzyPrice system is characterized by its operation that follows a fuzzy "what-if" scenarios (see Table 1). The heart of the inference procedure of this system lies in these scenarios. Market predictors are formed from these sets of scenarios. Fuzzy "what-if" scenarios are implemented along with fuzzy rules with the similar structure of the fuzzy "IF-THEN" rules. While managerial decision making, which is coming from human experts, remains the most qualitative knowledge input for the FuzzyPrice system, market research, and historical data are also valuable data sources [4].

Table 1. Characteristic comparison of the expert pricing tools

\begin{tabular}{l|l|l|l}
\hline Attributes & Price-Strat & Fuzzy Price & exPrice \\
\hline System Type & Hybrid Expert System & Hybrid Expert System & Expert System \\
\hline Operations & $\begin{array}{l}\text { "If-then" rules and price } \\
\text { scenarios responses }\end{array}$ & "What-If" scenarios" & "If-then" production rules \\
\hline $\begin{array}{l}\text { Pricing } \\
\text { Application }\end{array}$ & Multiple industries & Multiple industries & Multiple industries \\
\hline Unique feature & $\begin{array}{l}\text { Easy adaption of variants to } \\
\text { different consumer indus- } \\
\text { tries }\end{array}$ & $\begin{array}{l}\text { Scenario-oriented along } \\
\text { with sensitivity and profit } \\
\text { margin analysis }\end{array}$ & Flexibility and modularity \\
\hline $\begin{array}{l}\text { System } \\
\text { Improvements }\end{array}$ & $\begin{array}{l}\text { Large scope for improving } \\
\text { profitability for all Price- } \\
\text { Strat family of tools }\end{array}$ & $\begin{array}{l}\text { Weighting of each com- } \\
\text { petitor's actions and ex- } \\
\text { tending variable to } \\
\text { include variable such as } \\
\text { advertisement }\end{array}$ & $\begin{array}{l}\text { Presented as a system } \\
\text { open for new production } \\
\text { rules extension without } \\
\text { modifying the existing } \\
\text { ones }\end{array}$ \\
\hline
\end{tabular}

\section{3 exPrice Expert System}

The exPrice expert system is a product and pricing expert system in which four variables were used during the development [5]. The variables are the elasticity of demand in relation to price, market structure, level of business activities, and business goals. Depending on the numerical value of the elasticity coefficient, it can take any of "low," "significant," or "high" as a fuzzy variable. Market structure, which is the second variable is a determinant of the number of products and offerings in the market. These offerings can be "high," "significant," and "low." The third variable in the exPrice expert system is the intensity of the firm's business activities. The most important is the fourth variable, which is the business goal. This determines the strategic intent behind the price move. 
The strategic intent behind the price move can be customer retention, acquisition, or response to the competitive landscape and activities. The exPrice expert system can suggest the following pricing move to the business (a) retain existing price, maintain price with promotional activities, equalize price with the competition, or decrease the price by a certain percentage point. It contains production rules (see Table 1), and facts that provide insights and help to marketers in pricing and product management $[5,23]$.

\section{Conclusion}

Price-Strat is a knowledge-based and generic pricing tool that takes care of pricing processes. On the other hand, FuzzyPrice and exPrice are hybrid expert systems that contain numbers of fuzzy expert systems layered together in a block and systematic manner [3, $4,5]$. Through the various variants of Price-Strat, experienced and non-experienced marketers across many industries can leverage the pricing tool to determine their price points. The variants of Price-Strat are PriceNet used by gasoline stations, Retail Price Optimizer for retail, TelPrice for the mobile industry, and BankPrice system for the banking industry [22].

During the pricing decision-making process on each of the products of the firm within a market when using the FuzzyPrice system, all the competitor's pricing moves along with all their product mix serve as input to the system [4]. As for the exPrice expert system, pricing decisions are made following the elasticity of demand, market structure, business activity intensity, and the firm business goals and objectives. All the three expert pricing tools that are discussed in this paper have achieved very good results across several vital pricing strategic objectives [5]. However, further improvements in the system can still lead to better accuracy of the recommended price points with a better impact on the customer experience. The systems can achieve this depending on the expert knowledge and historical data availability. This is an exciting area for future work.

One notable limitation in this study is the inability to experiment and evaluate the three pricing tools along their price adjustment performance. This is due to the uniqueness of the expert pricing tools toward specific industry, and perhaps, products and services. However, evaluation and comparison of the pricing tools are measured along their characteristics and development.

\section{References}

[1] Enache IC. Fuzzy logic marketing models for sustainable development. Bulletin of the Transilvania University of Brasov, Series V: Economic Sciences. 2015; 8(57).

[2] Rekettye G, Liu J. Pricing: The New Frontier. Transnational Press London; (2018).

[3] Singh MG, Bennavail JC. Price-Strat: A knowledge support system for profitable decision-making during price wars. Information and Decision Technologies. 1993; 19: 227-296.

[4] Tzafestas SG, Raptis SN, Moschos NA. A hybrid pricing expert system based on fuzzy reasoning. Foundations of Computing and Decision Sciences. 1999.

[5] Bijakšić S, Markić B, Bevanda A. Expert pricing system as part of marketing mix. 2017; 50: 3-4.

[6] Rhuggenaath J, Akcay A, Zhang Y, Kaymak U. Fuzzy logic-based pricing combined with adaptive search for reserve price optimization in online ad auctions. IEEE International Conference on Fuzzy Systems Institute of Electrical and Electronics Engineers. 2019. 
[7] Martinez-Lopez F, Jorge C. Marketing intelligent systems for consumer behavior modeling by a descriptive induction approach based on genetic fuzzy systems. Industrial Marketing Management. 2009; 38: 714-731.

[8] Ektay T, Cengiz K. Evaluation of Design requirements using fuzzy outranking methods. International Journal of Intelligent Systems. 2007; 22: 1229-1250.

[9] Temponi C, John Y, Amos T. House of quality: a fuzzy logic-based requirements analysis. European Journal of Operational Research. 1999; 117: 340-354.

[10] Maruvada DP, Bellamkonda RS. Analyzing the passenger service quality of the Indian Railways using railqual: examining the applicability and technology. 2010; 1: 478-482.

[11] Yogi K. An empirical and fuzzy logic approach to product quality and purchase intention of customer. Pacific Science Review, Humanities and Social Sciences. 2015; 57 -69.

[12] Razak T, Hashim M, Noor N, Halim I, Shamsul N. Career path recommendation system for UiTM Perlis Students using fuzzy logic. IEEE. 2014; 978-1-4799- 4653-2/14.

[13] Susanto S, Vasant P, Bhattacharya A, Fransiscus RP. Fuzzy LP with a non-linear MF for product-mix solution, a case-based re-modeling and solution. Proceedings of the $9^{\text {th }}$ joint Conference on Information Science. 2006.

[14] Aly S, Ivan V. Fuzzy expert marketing-mix model. Agricultural Economics. 2005; 51: 69-79.

[15] Xiong Y, Li G, Kiran JF. Dynamic pricing model and algorithm for perishable products with fuzzy demand. Applied Stochastic Models in Business and Industry. 2010; 26: 758-774.

[16] Bennouna G. Tkiouat M. Fuzzy logic approach applied to credit scoring for microfinance in Morocco. Procedia Computer Science. 2018; 127: 274-283.

[17] Zadeh L. Making computers think like people, IEEE Spectrum. 1984; 26-32.

[18] Ruiz-Mezcua B, Garcia-Crespo A, Lopez-Cuadrado JL, Gonzalez-Carrasco I. An expert system development tool for non-AI experts. Expert Systems with Applications. 2011; 38: 597-609.

[19] Omid M, Lashgari M, Mobli H, Alimardani R, Mohtasebi S, Hesamifard R. Design of fuzzy logic control system incorporating human expert knowledge for combine harvester. Expert Systems with Applications. 2010; 37: 7080-7085.

[20] Tavana M, Hajipour V. A practical review and taxonomy of fuzzy expert systems: methods and applications. Benchmarking: An International Journal. 2019; 27: 81-136.

[21] Thaker S, Nagori V. Analysis of fuzzification process in fuzzy expert system. Procedua Computer Science. 2018; 132:1308 -1316.

[22] Cassaigne N, Singh MG. Intelligent decision support for the pricing of Products and services in competitive consumer markets. IEEE Transactions on Systems, Man and Cybernetics - Part C: Applications and Reviews. 2001; 31(1).

[23] Nan G, Wang S, Li Z, Dou R. A novel pricing strategy for mobile broadband carriers using two-stage Stackelberg model. Knowledge-based system. 2018; 142: 45-57. 